\title{
Agathe Sultan, Tombeaux de musiciens à la fin du Moyen Âge
}

\section{Maria Colombo Timelli}

\section{(2) OpenEdition}

1 Journals

\section{Édition électronique}

URL : https://journals.openedition.org/studifrancesi/26033

DOI : 10.4000/studifrancesi.26033

ISSN : 2427-5856

Éditeur

Rosenberg \& Sellier

\section{Édition imprimée}

Date de publication : 1 avril 2007

Pagination : 157

ISSN : 0039-2944

\section{Référence électronique}

Maria Colombo Timelli, « Agathe Sultan, Tombeaux de musiciens à la fin du Moyen Âge », Studi Francesi [En ligne], 151 (LI | I) | 2007, mis en ligne le 30 novembre 2015, consulté le 23 novembre 2021. URL: http://journals.openedition.org/studifrancesi/26033; DOI : https://doi.org/10.4000/studifrancesi. 26033

Ce document a été généré automatiquement le 23 novembre 2021.

\section{(c)}

Studi Francesi è distribuita con Licenza Creative Commons Attribuzione - Non commerciale - Non opere derivate 4.0 Internazionale. 


\title{
Agathe Sultan, Tombeaux de musiciens à la fin du Moyen Âge
}

\author{
Maria Colombo Timelli
}

\section{RÉFÉRENCE}

AGATHE SULTAN, Tombeaux de musiciens à la fin du Moyen Âge, in La mort écrite. Rites et rhétoriques du trépas au Moyen Âge. Textes recueillis par Estelle Doudet, Paris, PUPS («Cultures et civilisations médiévales», 30), 2005, pp. 157-171.

1 À partir d'un corpus de 'tombeaux' (la double ballade sur la mort de Machaut d'Eustache Deschamps, la 'déploration' sur la mort de Binchois de Johannes Ockeghem, la lamentation sur la mort d'Ockeghem de Guillaume Cretin, deux épitaphes de J. Ockeghem de Jean Molinet), A. S. montre que ce genre poétique / musical se caractérise à la fin du Moyen Âge par la tension entre deux esthétiques opposées: celle du texte, dont le style lapidaire est l'analogue de la pierre tombale, et celle du chant, mouvement par définition. 